\title{
Conceptualisation of knowledge construction in community service-learning programmes in nursing education
}

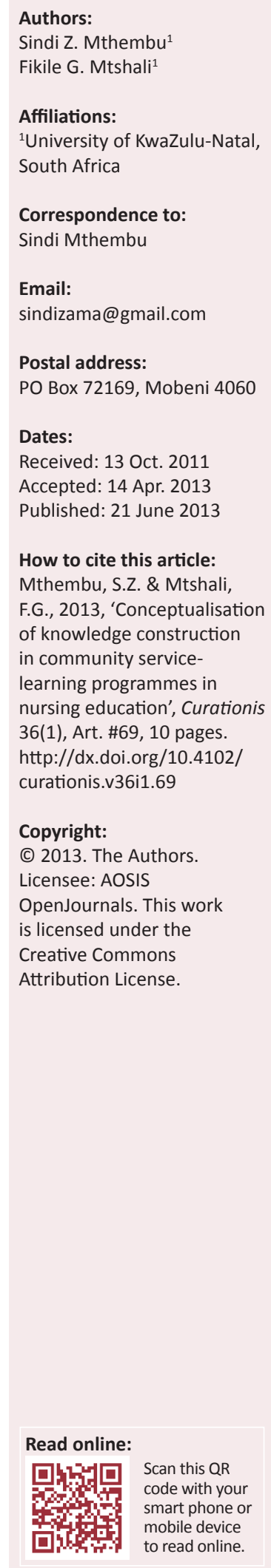

Background: Practices in higher education have been criticised for not developing and preparing students for the expertise required in real environments. Literature reports that educational programmes tend to favour knowledge conformation rather than knowledge construction; however, community service learning (CSL) is a powerful pedagogical strategy that encourages students to make meaningful connections between the content in the classroom and real-life experiences as manifested by the communities. Through CSL, learning is achieved by the active construction of knowledge supported by multiple perspectives within meaningful real contexts, and the social interactions amongst students are seen to play a critical role in the processes of learning and cognition. This article reflects facilitators' perspective of the knowledge construction process as used with students doing community service learning in basic nursing programmes.

Objectives: The aim of this article was to conceptualise the phenomenon of knowledge construction and thereby provide educators with a shared meaning and common understanding, and to analyse the interaction strategies utilised by nurse educators in the process of knowledge construction in community service-learning programmes in basic nursing education.

Method: A qualitative research approach based on a grounded theory research design was used in this article. Two nursing education institutions were purposively selected. Structured interviews were conducted with 16 participants.

Results: The results revealed that the knowledge construction in community service-learning programmes is conceptualised as having specific determinants, including the use of authentic health-related problems, academic coaching through scaffolding, academic discourse-dialogue, interactive learning in communities of learners, active learning, continuous reflection as well as collaborative and inquiry-based learning. Upon completion of an experience, students create and test generated knowledge in different contextual health settings.

Conclusion: It was concluded that knowledge is constructed by students as a result of their interaction with the communities in their socio-cultural context and is mediated by their prior concrete experiences. The implication of this is that students construct knowledge that can be applied in their future work places.

\section{Introduction}

Learning is achieved by the active construction of knowledge supported by multiple perspectives within meaningful real contexts, and the social interactions amongst students are seen to play a critical role in the processes of learning and cognition. Jonassen (2000) points out that teaching is a process of enabling students to construct their own meaning from their past experiences by providing a platform to learn from those experiences and guiding the meaning making process. Educators have a role to facilitate the construction of knowledge through active learning pedagogies (Jonassen 2000).

Contemporary learning theories, such as constructivism, emphasise the notion that learning is an active process by which this knowledge construction is supported, rather than a process of knowledge transmission (Schellens \& Valcke 2006). Constructivist teaching facilitates students' creation of their own knowledge as they are given more freedom to reflect on the problems together and to generate original ideas. Knowledge constructed in real settings promotes critical thinking, which allows the learner to integrate concepts within and between disciplines, to represent concepts in multiple forms and to justify, defend and reflect on these concepts (Yueng \& Hau 2006). Windschitl (2002) claims that the knowledge construction process starts with the view that knowledge must be constructed within the cognitive structure of every individual, so that it is fundamentally personal, whilst being dependent on experiences in the learning environment and on social interactions. 
In South Africa, a number of academic institutions place their students in community settings for experiential learning purposes through community service learning (CSL). Learning in community settings is assumed to inform knowledge construction in the classroom as well as the curriculum content (Mtshali 2009). CSL is marked by a paradigm shift from teacher-dominated learning to learning where students play an active role in the process of knowledge construction (Lazarus 2005).

\section{Problem statement}

Literature (Lu \& Jeng 2006; Moore \& Marra 2005; Schellens \& Valcke 2006) reveals concerns regarding the process of knowledge construction. Educational programmes tend to favour knowledge conformation rather than knowledge construction ( $\mathrm{Lu} \&$ Jeng 2006). Higher-education settings offer unique opportunities and challenges to create a model of teaching and learning that is congruent with espoused beliefs about knowledge and the way it is constructed. However, according to Mandl, Gruber and Renkl (1996), practices in higher education have been criticised for not developing and preparing students for the expertise required in real environments. In this article, the author therefore explores the facilitators' perspective of the process of knowledge construction in CSL programmes in basic nursing education.

\section{Aims of the study}

Most of the studies conducted on knowledge construction are in the area of online teaching (Garrison, Anderson \& Archer 2003; Gunawardena, Lowe \& Anderson 1997; Lu \& Jeng 2006; Moore \& Marra 2005; Schellens \& Valcke 2006). Very few, if any, address the process of knowledge construction in other forms of teaching and learning. Therefore, the purpose of this article is to provide nurse educators at the selected nursing education institutions (NEIs) that participated in this study with a shared meaning and conceptualisation of knowledge construction and a common understanding.

\section{Background}

The paradigm shift in teaching and learning to CSL can be traced back to the time of philosophers such as John Dewey (1859-1952), who emphasises that learning takes place within a meaningful context that allows students to build upon the knowledge they already have. Dewey (1916) points out that authentic problems make the subject matter relevant and interesting to the learner. In authentic environments, students collaboratively construct knowledge and negotiate meaning through socially interactive conversation amongst participants and facilitators during class interactions. The facilitator serves also as a coparticipant who constructs knowledge with students. The construction of knowledge will therefore be based on realistic problems and needs expressed by the community.

Real problems serve as starting points in the process of knowledge construction, and dealing with problems is observed throughout the knowledge construction process.
According to Callister and Garbett (2000), the use of authentic problems makes CSL a powerful pedagogical strategy that encourages students to make meaningful connections between the content in the classroom and real-life experiences as manifested in the community. Learning through solving real problems promotes practicality and relevance of the knowledge constructed (Hmelo-Silver \& Barrows 2006).

\section{Trends}

The different understandings of knowledge construction and models of the knowledge construction process are presented in this section with the aim of providing a basis of how the facilitation of knowledge construction in CSL programmes occurred.

Understandings of knowledge construction: Knowledge construction is a mental act of acquiring new knowledge, as well as communicating existing knowledge. According to Hammett and Collins (2002), knowledge construction occurs when students engage in meaningful activities, activities that are authentic in real situations. Knowledge is the product of interaction between our ideas about the world and our experiences of the world (Duffy \& Cunningham 1996). Von Glasersfeld (1995) proposes four essential epistemological tenets of knowledge construction, (1) knowledge is not passively accumulated, but rather the result of active cognising by the individual, (2) cognition is an adaptive process that functions to make an individual's behaviour more viable given a particular environment, (3) cognition organises and makes sense of one's experience and is not a process to render an accurate representation of reality and (4) knowing has roots in biological or neurological construction as well as in social, cultural and language-based interactions. It is therefore acknowledged that the student plays an active role in the personal creation of knowledge. The importance of experience (both individual and social) in this process of knowledge creation, and the realisation that the knowledge created will vary in its degree of validity, is an accurate representation of reality (Von Glasersfeld 1995).

Models of knowledge construction: The facilitation of knowledge construction in the classroom can be a challenging experience for the teacher. In this section the two models for knowledge construction as theoretical frameworks for assessing the levels of knowledge that is socially constructed are presented and compared.

The practical inquiry model (PIM), which is based on Dewey's concept that education is the collaborative reconstruction of experience, is proposed by Garrison et al. (2003). According to this model, an educational experience intended to achieve higher-order critical thinking outcomes is best embedded in a community of inquiry. This four-phased model includes the triggering event, exploration, integration and the generation of a solution or hypothesis of a dilemma or problem. The phases might continue in a cycle with the solution or hypothesis leading to further problems and new triggering events. 
$\mathrm{Lu}$ and Jeng (2006) reported on another frequently used knowledge construction model, namely the interaction analysis model (IAM). The IAM, developed by Gunawardena et al. (1997), suggests that knowledge construction consists of five phases, namely sharing or comparing observations, dissonance, negotiation, construction, testing and application.

Lu and Jeng (2006), when comparing the IAM and PIM, state that both these models provide a socially constructed theoretical framework for assessing the levels of knowledge. They are of the opinion that the IAM is stronger than the PIM because it identifies more specific types of cognitive activities in critical discourse such as argument, resource and evidence of changes. As a result, the IAM provides researchers with more specific codes to investigate the knowledge construction process. It further provides a holistic view of the discussion flow and knowledge construction and is more practical for analysing a discourse ( $\mathrm{Lu} \&$ Jeng 2006). This is true for the CSL group process, in which students bring to the discussion the health-related problems identified in the community, they prioritise and analyse the problems and find solutions to the problems. According to the IAM, students complete the process of knowledge construction by actually making practical achievable plans to help communities solve their problems and they also implement those plans through community interventions.

Lu and Jeng (2006) conducted a study to investigate how teachers constructed new knowledge, the extent of knowledge construction achieved and how instructors participated in and facilitated the online discussion to affect knowledge construction. The study demonstrates that most educational programmes tend to favour knowledge conformation rather than knowledge construction, but sometimes facilitation approaches are used which are helpful for enhancing knowledge construction. Moore and Marra (2005) reveal that most learning activities in classroom interactions remain at Phases I and II of the IAM, which include only the discovery and exploration of dissonance or the inconsistency amongst ideas, concepts or statements. Moore and Marra (2005) point out that students do not reach the phases of negotiation and construction, or testing and application of new knowledge. According to these researchers, less knowledge construction means less higher-order thinking skills.

\section{Research objectives}

The objectives of this research study were to (1) explore nurse educators' understanding of the phenomenon of knowledge construction in community service-learning (CSL) programmes and (2) analyse the interaction strategies utilised by nurse educators in the process of knowledge construction in CSL programmes in basic nursing education.

\section{Definition of key concepts}

Knowledge: Knowledge is defined by Davenport and Prusak (1998:102) as a 'fluid mix of framed experience, values, contextual information, and expert insight'. For the purpose of this article, the term knowledge is used in the sense of anything that is known by a person.
Knowledge construction: Knowledge construction is a mental act of acquiring new knowledge, as well as communicating existing knowledge. According to Hammet and Collins (2002), knowledge construction occurs when students engage in meaningful activities, activities that are authentic in real situations.

Community service learning (CSL): CSL is an educational approach to teaching and learning in which students participate in an organised service activity that meets identified community needs. According to Lazarus (2005), CSL engages students in activities where both the community and the student are primary beneficiaries, and where the goals are to provide a service to the community and, equally, to enhance student learning through the provision of this service.

Nursing education institutions (NEIs): In the context of this study, the NEIs are the two university-based nursing schools or departments that participated. These institutions were identified for inclusion in this study because of their well established and widely renowned CSL programmes (Mtshali 2009).

\section{Significance of the study}

Literature indicates that most of the studies conducted on knowledge construction are in the area of online teaching and few, if any, address the phenomenon of knowledge construction in other forms of teaching or learning. The authors hope that the results of this research study may bring some understanding of the process of knowledge construction in CSL, especially because learners bring raw information from community settings to the classroom which in turn becomes the curriculum content. The findings may contribute to the enrichment of skills for nurse educators who conduct group discussions. Furthermore, the authors hope that this study, which is one of the few in this field, will provide baseline data that may be used for further research. Moreover, the results of this study may provide a shared meaning of the phenomenon of knowledge construction in CSL programmes in basic nursing education in South Africa and, thus, advance theoretical propositions to guide policy formulation and implementation as highereducation institutions in the country continue their efforts for innovative educational programmes.

\section{Research methodology Design}

A qualitative approach based on a grounded theory research design was adopted for the research on which this article is based. This research study entered the traditions of grounded theory, both in the research process and the analysis of data. Grounded theory, sometimes referred to as the constant comparative method, is a qualitative method attributed to Glaser and Strauss (1967). The multi-layered process of abstraction of data in grounded theory explores previously identified concepts whilst generating new ones. 
The analysis proceeds from low-level descriptions to indepth explorations, which are referenced at every level by other categories from the analysis. This allows for a continual comparative analysis, which ensures a conceptually rich theoretical account of the data (Strauss \& Corbin 1990).

Grounded theory makes its greatest contribution in areas where little research has been done and when new viewpoints or gestalts are needed to describe a familiar phenomenon that is not clearly understood (Chenitz \& Swanson 1986). Grounded theory was appropriate in this study because very little has been done in terms of research aimed at understanding how knowledge is constructed and conceptualised in CSL nursing programmes, in South Africa and globally.

\section{Materials}

Two nursing education institutions (NEIs) that are well established and are recognised countrywide for their CSL in basic nursing education programmes were purposively selected to participate. The selection of participants from the NEIs was dependent on the role they play in the CSL programmes. In the South African context, all pre-registration nursing programmes run for a period of four years. At each year level there is usually an academic level coordinator who is responsible for the administrative work at that particular level. There is also a programme director who is responsible for overseeing the entire undergraduate nursing programme. The heads of department and deputy heads of the NEIs were interviewed, as well as the programme directors and coordinators at the level where the CSL component was offered, and the facilitators (or lecturers), including clinical facilitators, where applicable, who were involved in the CSL programmes. The interview sample comprised 16 participants. In NEI-A, the sample comprised the deputy head of the school, the basic nursing programme academic coordinator, the second-year level coordinator (the level offering CSL) as well as four facilitators for this level, bringing the total of participants at this NEI to seven. In NEI-B, a total number of nine participants were interviewed. These were the head of the school, the undergraduate programme director, four level coordinators (one for each level of the basic nursing programme) who also acted as facilitators, two additional facilitators and one clinical facilitator.

The experience of the participants in CSL was not taken into consideration - the researcher wanted to accommodate as much numbers of participants as possible to allow for deeper and broader scope of data collected. The students involved in the CSL programme were not interviewed, but observations of their classroom sessions and community engagement activities interaction were carried out and the process of learning noted thus.

\section{Data collection methods}

The process of knowledge construction in CSL was observed as it occurred at community learning sites and also in the classroom setting. The collection of observations made translated how students learnt from the communities and how the authentic learning was transferred to the classrooms and then back to the communities. During each classroom session observed, events were documented by the researcher as they occurred in the form of field notes. Observation of students in community learning sites and also in the classroom assisted the researcher in gaining insight into the practice of CSL. The focus was on how students gained knowledge and experience by their interactions with the communities in need of health interventions and on how this knowledge and experience, once gained, was taken back to the classroom for further reflection, application and evaluation. The lecturers shared with the researcher their understanding of the meaning behind the practice of CSL and the process of knowledge construction in both the community and the classroom. Questions that served as outlines for the interviews were prepared. The following questions were asked:

- What is your understanding of the concept knowledge construction within the context of CSL in your institution?

- What are the core characteristics of the knowledge construction process in CSL in your institution?

- Please briefly describe your school's service-learning and/or community-based basic nursing education programme.

- How does learning from the community settings inform classroom teaching/learning?

- Please explain the process that you follow when conducting classroom sessions?

- What is your role during classroom interaction?

- What role is played by the students during the classroom sessions?

- Does your group ever engage in a dialogue to such an extent that new information emerges from that process? Can you explain this process?

- At what stage do you say that learning has taken place?

- What facilitates or hinders the process of knowledge construction?

Structured interviews that were conducted were mainly based on data that had emerged during observation at each site so as to cross-check, fill gaps and verify categories and concepts that had emerged from the data of each site. The interviews addressed questions related to the nature of learning experiences used, community-based student learning experiences or activities, teaching and learning processes, and the roles of those involved in the programme and their community involvement. Interviews were then transcribed and coded using thematic analysis.

The copies of documents pertaining to the CSL programme were requested for analysis. These included documents regarding the philosophy, vision and mission statements of the NEIs, conceptual frameworks, programme and level or course outcomes and its assessment criteria as well as the evaluation instruments of the programme. According to Wilson (1997), the agency's perspective and interpretation of the phenomena often emerges from the analysis of the 
documents. These documents were analysed in relation to the data that was emerging during observations and interviews. On-going and concurrent analysis of data, at this stage, yielded preliminary concepts and constructs describing CSL processes and practices as understood and practised by the selected NEIs. It also gave insight in how students applied the knowledge they had learnt in community settings when back in the classroom.

\section{Ethical considerations}

Permission to conduct this study was obtained from the University of KwaZulu-Natal Faculty of Health Sciences Research Ethics Committee and the heads of the two NEIs that participated in this study. The researcher obtained the informed consent of all the participants in the study. Although students were not regarded as participants, their interactions and participation in classroom and group activities would be observed and, because of this, they were informed and their permission was sought. The researcher introduced herself to the participants (nursing education institution staff, students and community members, where and whenever relevant) and informed them of the nature and extent of the research prior to commencement. The researcher, with the lecturers concerned, ensured that students were not coerced into participating in the research (Trochim 2002). In this research study, the researcher had to guarantee that no participants were put in a situation where they might be harmed, either physically or psychologically, as a result of their participation (Trochim 2002). The researcher ensured the confidentiality and anonymity of the participants. All data collection devices, that is, audiotapes and transcripts, were confined to the researcher. The researcher made it clear that the participants' names would not be used for any purposes, nor would information be shared that revealed their identity in any way.

\section{Trustworthiness}

The researcher used several measures to achieve credibility. Data and categories discovered were discussed with the research supervisor at regular intervals and other experts in qualitative research were consulted. Triangulation was also done by using three data collection techniques, namely in-depth individual interviews (with memos and audio recording), analysis of documents and observation of group sessions with the use of field notes. The documents that were analyses included the mission, vision and philosophy of the NEIs; programme and level outcomes; teaching methodology; curriculum content and group process evaluation forms.

Membership check, which refers to the researcher's ability to recheck the participants to validate the accuracy of the information given and recorded, was also applied. The researcher went back to those interviewed to verify if the recorded data was accurate or needed correction or elaboration on construct.

Dependability was ensured by conducting data quality checks or audits, peer review coding and consultation of qualitative research experts. The qualitative research experts were consulted to monitor the data collection process, as well as the analysis and interpretation of the data.

Confirmability was promoted by taking detailed field notes, by taping and transcribing interviews verbatim to identify variations in responses and by making field notes available for audit checks and verification. This was done following data collection, where the field notes were made available to interviewees for cross-checking and verification.

Transferability was ensured by using purposive sampling, giving a detailed description of the context or setting and providing detailed descriptions of the whole process of the research study.

\section{Presentation of findings and discussion}

In this section, the perceptions of the lecturers of the process of knowledge construction in CSL will be reported on as well as observed student group processes both in the community and in the classroom.

\section{Conceptualisation of the phenomenon 'knowledge construction'}

Different characteristic elements emerged through which knowledge construction in CSL programmes manifested, such as academic discourse-dialogue, active learning, authentic health-related problems, cognitive coaching (scaffolding), collaborative learning, continuous reflection, interactive communities of learners and inquiry-based learning. The knowledge construction elements were observed both in the community and in the classroom settings. Community settings were reported to be ideal learning experiences that provide a context for learning which is meaningful and authentic. Learning activities in the community settings were based on solving real-life problems which had been identified in the communities. The rich and diverse community environments promoted learning through the investigation of community problems within authentic contexts and encouraged students to draw on live experiences. Hammet and Collins (2002) view knowledge as a social phenomenon, which is therefore socially constructed. Meeting communities and working towards identified community needs enlighten the students regarding different cultural, religious and traditional beliefs present in the types of communities where they will be working in future. The locus of this action must be where people live, work and need to be cared for and not only in the classroom.

The determinants of knowledge construction in CSL: It emerged that knowledge construction in community-based learning (CBL) is based on varied characteristic determinants as depicted in Figure 1.

Knowledge construction is grounded in authentic healthrelated problems: The use of authentic health problems 


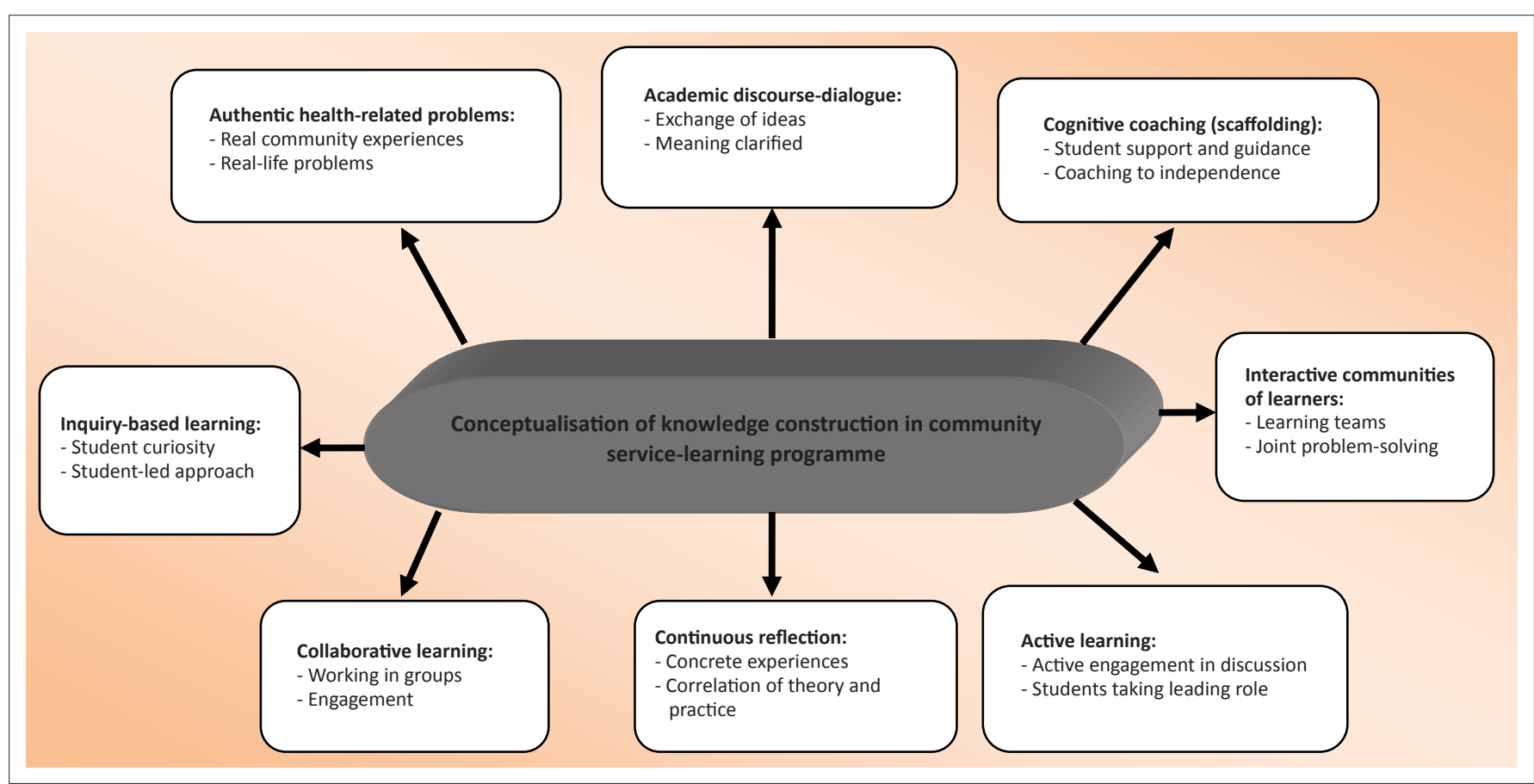

FIGURE 1: The determinants of knowledge construction in community service-learning programmes in nursing education.

from real-life settings emerged as central in the process of constructing knowledge in CSL basic nursing programmes. Knowledge construction, including all other learning activities, both in the classroom and in community settings, revolves around identifying and solving and fulfilling authentic community health-related problems and needs. According to Lombardi (2007), authentic health-related problems comprise complex learning tasks to be investigated by students over a sustained period of time, requiring significant investment of time and intellectual resources. The identified health problems drive the whole process of knowledge construction in CSL basic nursing programmes. The use of problems as central in knowledge construction in CSL programmes is not new. Dewey (1916) advocates the use of real-life problems in the curriculum as they promote development of problem-solving and critical thinking skills. According to Hmelo-Silver and Barrows (2006), learning through solving real problems promotes practicality and relevance of the knowledge constructed. Dewey (1916) is of the opinion that authentic problems make the subject matter relevant and interesting to the student. This means that the construction of knowledge is based on realistic problems and needs expressed by communities, as one of the participants indicated in the following excerpt:

'The use of real-life problems relates the educational environment to future professional practice and thus helps bridge the theory/ practice gap.' (A, female nurse educator)

An authentic learning environment is similar to the realworld application or discipline and it automatically brings into play multiple health disciplines as well as multiple individual, family and/or community perspectives, ways of thinking, ways of working and ways of learning with and in the community. One participant stated that:

'In authentic context, students acquire content and skills through the resolution of realistic problems ... [T] he knowledge and understanding that are developed in their realistic and complex situations are more easily retrieved when needed.' (B, female nurse educator)

Knowledge construction enhances academic discoursedialogue: Knowledge construction was characterised by the exchange of ideas, viewpoints and arguments as students discussed realistic community-based issues in group processes. It was observed during the knowledge construction process that the discussions were aimed at finding solutions that were relevant in that particular community context. Peterson (2010) maintains that dialogue between students within a group is critical in building shared meanings and definitions of a problem. Brooks and Brooks (1999) state that students should exchange their personal views, engage in dialogue and test their knowledge against the ideas of others, create and co-create knowledge based on empirical evidence shared in the group process. For knowledge to be created and co-created, academic discourse dialogue has to be effective, as expressed by a participant:

'Students' interactions during classroom discussions encourage students to critically analyse the data at hand for the purpose of constructing meaning and then validate knowledge through discourse and action.' (C, female nurse educator)

Discourse allowed assumptions to surface and be challenged. It was also noted that through vigorous class discussions, students were exposed to the sources of disagreements which then led to agreements or consensus, as highlighted in Peterson (2010). Jonassen (2000) states that by providing equal opportunities, all students developed a sense of ownership to newly constructed knowledge and reduced the tendency for them to think unidirectionally, as one participant mentioned:

'During active dialogue in class, students remember the core content better, and are able to align the data they have at hand with the with new information they didn't know before ... the more inquisitive and talkative some students are, the more the whole group or class will learn.'(A, female nurse educator) 
According to Schellens and Valcke (2006), the interactive process of knowledge construction enhances academic discourse. If students are given a chance to present what they think regarding theideas of others and are comfortable enough to express their own ideas, then meaningful dialogue will occur, and when meaningful dialogue takes place, meaningful construction of applied knowledge occurs (Brooks \& Brooks 1999). Freire (1972:72) states that ' $[w]$ ithout dialogue there is no communication, and without communication there can be no true education'. Sensitive to the 'silence of the oppressed', Freire (1972) frequently mentions the problem of silence and monologue and emphasised critical and liberating dialogue with people (Freire 1972).

Knowledge construction requires cognitive coaching and scaffolding: It emerged that the students required guidance, support and coaching from their teachers from time to time, so that they could cope with the learning issues emerging in group processes. Scaffolding was used as a means for cognitive coaching. McLoughlin and Luca (2001) point out that scaffolding is a form of assistance provided to students by a teacher that helps students to perform tasks that would normally not be possible to accomplish by working independently. Dennen (2008) is of the opinion that teachers are well placed to provide that support to students through cognitive coaching. As one of the participants stated:

'Cognitive coaching is purposive support given to students for the purpose of academic achievement ... [I]n our case, it is performed within groups in the classroom and in the communities.' (E, female nurse educator)

Scaffolding entails the gradual withdrawal of the teacher from the group process when the students can manage on their own (Ewell 2007). Towards the end of the semester it was observed that the students were used to the system and were more open-minded and more engaged in classroom discussions. Dennen (2008) emphasises that, as the teacher ceases scaffolding, the students take greater responsibility for facilitating the group processes. This requires them to be primary instigators in the construction of knowledge, with the teacher gradually handing over the responsibility to them. One participant stated:

'We provide some form of supportive guidance to students that help them to engage in group tasks ... to discuss up to the level that would normally not be possible to accomplish by working independently.' (B, female nurse educator)

Fading of scaffolding during knowledge construction occurs as students gain independence and no longer rely on the support of the facilitator to complete the learning tasks or issues at hand, as posited by Dennen (2008). Dennen is of the opinion that students actively engage at their current level of understanding up to the point where the support of the teacher is minimally required. It became clear from the observations that the facilitators actively and purposefully facilitated the process of learning up to a certain phase of development. Students were then encouraged to move slightly beyond to achieve the next level of learning, where they actively participated in their own construction process.
Knowledge construction is interactive in nature and takes place in communities of learners: Constructing knowledge was not uni-directional from the teacher to student, but as Lave and Wenger (1991) explain, it was multi-directional in nature with interactive engagements of the facilitator with the students and/or students with the community members. The students, facilitators and the community members form the communities of learners (CoLs). Lave and Wenger (1991) are of the view that knowledge construction in CoLs is embedded in real-world situations in which students function as part of a community, helping to solve real-world problems. Members of the CoLs were learning from each other. Community members were found to be knowledgeable with regard to the health-related problems existing in their communities and the ways of dealing with them at community level. Collins and Bielaczyc (2007) state that, because of the changing nature of health needs in society, students need to develop ways of dealing with complex issues and dynamic health problems that require different kinds of expertise that no one individual can ever provide. Students therefore need to work with and listen to the communities, be able to learn new things from a variety of resources and people, and be able to investigate, question and bring their learning back to the community. Similarly, Winberg (2006) is of the opinion that community members have a lot to offer to the students because the community members are better informed about the health issues and problems prevailing in the community. Community members are better equipped to judge which interventions and solutions will meet needs in addressing health-related community problems and issues. As CoLs, students were able to construct critical knowledge in terms of personal and collective knowledge creation. According to Smith (2010), CoLs link together several views from varying bodies of knowledge in such a manner that students have opportunities for a deeper understanding and integration of the material they are learning, and have more interaction with one another and with their teachers as fellow participants in the learning enterprise. Furthermore, Smith (2010) acknowledges that knowledge is constructed through the interactive sharing of ideas, constructive discussion and questioning, which implies the active role of all participants who share a common learning goal, as explained in the following excerpt:

'Students learn together by interacting with each other and with the facilitator ... [T] hey work together with communities to solve community identified problems ... [A]ll possible perspectives are considered jointly to find a common solution to problems identified.' (C, female nurse educator)

CoLs engage in interactions in an effort to collaborate and negotiate meaning and to develop informed knowledge. Maor (2007) sees interactivity as a dialectical relationship between individuals contributing to the knowledge and the social dynamics of the community. When individuals come together, such as in group discussions or group processes, the collective construction of knowledge undergoes continuous revision due to the critical cognitive input of others. As observed in this study, students interacted and negotiated meaning with each other through the creation of CoLs, which 
gave them opportunities for interaction to co-construct knowledge as stated by Jonassen (2000). It emerged that when students engaged in group processes, they form CoLs that share the same goals of fulfilling or solving community health needs or problems, as evidenced in the following excerpt:

'We strive for student interaction during learning in our approach ... [S]tudents learn from their experiences and those of their group mates. They also learn from the inputs during group discussions ... I say interactive because they learn together and from each other.' (E, female nurse educator)

Knowledge construction requires active learning: It emerged that the process of knowledge construction is in itself an active problem-solving process with the emphasis on action by the students. According to Oliver et al. (2002), learning is achieved by the active construction of knowledge supported by multiple perspectives in meaningful contexts. The students actively constructed their own knowledge rather than passively receiving information from teachers and textbooks. Knowledge is physically and actively constructed by students who are making their own representations of action in selected learning issues (Jonassen 2000; Maree, Van der Walt \& Van Rensburg 2009). Active learning techniques were manifested as students actively planned and implemented community interventions of the identified community problems. is In accordance with the results of this study, Stover (2001) is of the opinion that through active learning techniques students shed the traditional role as passive receptors as they learn and practice how to apprehend knowledge and skills and use these meaningfully. A participant expressed it thus:

'Students learn actively and accept more responsibility in community contexts ... [T] hrough careful deliberations in the community and in class, students look for meanings in identified problematic learning issues ... In essence, learning is more effective when it is an active process rather than a passive process.'(A, female nurse educator)

Knowledge construction promotes continuous reflective learning: It surfaced from the findings of this study that learning from the communities included continuous reflection of students on their community experiences. Reflections incorporated all the experiences students brought to class from the community surveys, family studies and epidemiological surveys. Schön (1987), an influential writer on reflection, describes reflection as a creative process that organises one's thinking and that happens mainly in two ways: reflection in action and reflection on action. In CSL programmes, it was observed that the students reflected in action as they worked in the communities and with the communities to clarify and find solutions to community problems and had to change their ways of thinking to address these new community tasks. Reflection on action is looking back after the event whilst reflection in action takes place during the event. Schön (1987:26) states the following: 'We reflect on action, thinking back on what we have done in order to discover how our knowing-in-action may have contributed to an unexpected outcome'. Students reflected on action as they evaluated the community intervention projects and what had been done in order to discover how their knowing-in-action may have contributed to an unexpected outcome, as stated by one of the participants:

'Students keep journals where they record how they felt about the encounter with the community and about their community projects, the visuals and verbal reactions of others to the experience.' ( $C$, female nurse educator)

During knowledge construction, concrete and prior learning experiences were promoted whereby the identification of community health problems and their interrogation in the classroom facilitated correlation of theory and practice. In line with these findings, Jakovljevic (2002) points out that reflection on learned experience concretely connects an experience to the learning associated with it. The problems that students identified from the community settings were dealt with in the classrooms with the aim of integrating what was occurring in the community with the theoretical basis of the discussions in class. Savery (2006) echoes the findings of this study as it emerged that students make connections between community learning experiences, theoretical grounding of the learned experiences, and the real world and its application to community contextual settings. According to Savery (2006), reflection is the link between learning and service, the ability to step back and be thoughtful and analytical about what one is doing.

Through reflection, academic and democratic solutions were considered and then applied to the problem in the form of community service. According to Savery (2006), reflection is the core component that provides the connection between what is learned in the classroom and the application of that learning to the particular community problem. Construction of knowledge in the context of this present article emerged as a result of an active process of articulation and reflection within an authentic context. Jonassen (2000) asserts that knowledge created is a product of the mind and results from an individual's experiences with and interpretation of the context. One of the participants mentioned that:

'Reflection makes students experts of their own learning ... [O] ur role as facilitator is to help create situations where students feel safe to question and reflect on their own learning processes, either as individuals or as groups ... Thinking about learning experiences in terms of what one understands and how one learns is a critical feature because it allows for knowledge to be created.' (E, female nurse educator)

Knowledge construction is collaborative in nature: Through collaborative learning, students constructed jointly and shared their perspectives to reach a deeper understanding of community problems. Students engaged in collaborative discussions of learning issues until they reached a common understanding of the issues at hand. The consensus reached was regarded as knowledge in their context. Jonassen (2000) posits that knowledge construction in community-based learning contexts is collaborative and embeds students in meaningful contexts. Collaborative knowledge construction enhances an active give and take of ideas between students rather than one student passively learning from the other. This type of engagement emerged as critical for students 
to construct knowledge, especially as groups, through collaborative problem-solving strategies. In line with these findings, other researchers (Bradshaw \& Lowenstein 2007; Jonassen 2000; Stover 2001) are of the view that knowledge construction is always discursive in nature and thus enhanced by collaborative group processes. The teamwork amongst students that occurred through the collaborative process of knowledge construction aided in developing, testing and evaluating different beliefs and hypotheses for posed problems within learning contexts; students were enabled to build new and modify existing knowledge structures, as posited by other researchers (Bradshaw \& Lowenstein 2007; Savery 2006; Stover 2001). This was indicated in the following quotes from some of the participants:

'Collaboration amongst students themselves promotes knowledge to be constructed collaboratively ... [W] hen students review and reflect on their learning processes together, they can pick up strategies and methods from one another.' (A, female nurse educator)

'Working together is necessary ... consultation and cooperation with each other is imperative ... Collaboration helps students to be active participants of the reflective learning environment ... it involves forming of partnership, sharing of information, cooperation and consultation amongst the students themselves, with different stakeholders in the community and with different university departments.' (D, female nurse educator)

Knowledge construction requires inquiry-based learning: Dewey (1916) believes that education begins with the curiosity of students. Knowledge construction, according to the findings of this particular study, is manifested by the inquisitive nature of students. Curiosity in the context of this study was observed in the classroom activities, which were student centred and focused on questioning and probing students for the purpose of stimulating inquisition. Inquiry leads to critical thinking and problem-solving. One participant expressed it as follows:

\begin{abstract}
'As students explore the topic, inquiry into the topic comes in, and students will use different means to reach solutions ... then conclusions are drawn by students and as exploration continues, they revisit those conclusions ... Exploration of the questions through inquiry leads to more questions and, eventually, to new knowledge.' (B, female nurse educator)
\end{abstract}

According to Savery (2006), inquiry-based learning activities begin with a question. Each question is then followed by investigating solutions, creating new knowledge as information is gathered and understood, discussing discoveries and experiences and reflecting on newly found knowledge. It surfaced that the inquisitive nature of students provided a framework for knowledge creation as students independently gained not only the knowledge and skills but also the disposition to use those skills, along with an understanding of their own responsibilities in the communities, as stated by Savery (2006). Inquiry encouraged a student-led, hands-on approach where students practiced the scientific method of authentic problem solving. Students construct knowledge as they become involved in questioning and solving real-life issues in communities, provided such opportunities are made available for them (Savery 2006). Students lead their own learning through inquiry-based interactions in the classroom.

In summary, this section indicated that knowledge construction in CSL is manifested in terms of different determinants, including grounding in authentic healthrelated problems, enhancement of academic discoursedialogue, cognitive coaching and scaffolding of students until they are well grounded in the group process and the interaction of students with teachers, other students and community members as communities of learners. In the classroom, there is active learning, continuous reflection, collaborative learning and inquiry-based learning.

\section{Recommendations}

To facilitate knowledge construction, it is recommended that CSL programmes be used to provide a context for learning which is meaningful and authentic. The collaboration of student-to-student, student-to-teacher and studentto-community members leads to the development of communities of practice characterised by knowledge sharing, in which the teacher becomes a coach or mentor rather than the holder of knowledge.

\section{Conclusion}

As much as it is known that knowledge is constructed within the cognitive structure of every individual so that it is fundamentally personal, facilitators revealed in this article that it is dependent on learning experiences gained by social interactions. Lecturers participating in this study indicated that meeting communities and working with community needs enlighten students regarding different cultural, religious and traditional beliefs present in the types of communities where they will be working in future. The locus of the students' action must be where people live, work and need to be cared for and not only in the classroom.

The discussion of the research findings revealed that knowledge is generated in real-life experiences that provide authentic, raw content for the students. Learning issues emerged from current realistic community problems that serve as basis for authentic learning experiences. Students engage in interactive learning discourse as communities of learners. Upon completion of a community service-learning experience, students create and test generated knowledge in differing contextual health settings.

It is concluded that knowledge is constructed by students as a result of their interaction with the communities in their sociocultural context and is also mediated by their prior concrete experiences. Knowledge construction in CSL programmes therefore takes place in an environment characterised by exposure to authentic health-related community problems. 


\section{Acknowledgement}

The National Research Fund is acknowledged for the financial support in this study.

\section{Competing interests}

The authors declare that they have no financial or personal relationship(s) which may have inappropriately influenced them in writing this article.

\section{Authors' contributions}

This article is part of the doctoral study by SZM (University of KwaZulu-Natal) and was promoted by NGM (University of KwaZulu-Natal).

\section{References}

Bradshaw, M. \& Lowenstein, A., 2007, Innovative teaching strategies in nursing and related health professions, Jones \& Bartlett, Sudbury.

Brooks, J.G. \& Brooks, M.G., 1999, In search of understanding: The case for constructivist classrooms, Association for Supervision and Curriculum, Alexandria.

Callister, L.C. \& Garbett, D., 2000, 'Enter to learn, go forth to serve: Service learning in nursing education', Journal of Professional Nursing 16(3), 177-183. http://dx.doi. org/10.1053/PN.2000.6177, PMid:10860316

Chenitz, W.C. \& Swanson, J.M., 1986, From grounded theory to practice, AddisonWesley, Menlo Park.

Collins, A. \& Bielaczyc, K., 2007, Learning communities in classrooms: A reconceptualization of educational practice in instructional design theories and models, Lawrence Erlbaum, Mahwah.

Davenport, T. \& Prusak, L., 1998, Working knowledge: How organisations manage what they know, Harvard Business School Press, Boston.

Dennen, V.P., 2008, 'Cognitive apprenticeship in educational practice: Research on scaffolding, modelling, mentoring and coaching as instructional strategies', Educational Technology \& Society 3(3), 813-828.

Dewey, J., 1916, Democracy and education, The Free Press, New York.

Duffy, T. \& Cunningham, D., 1996, 'Constructivism: Implications for the design and delivery of instruction', in D.H. Jonassen (ed.), Handbook of research for educational telecommunications and technology, pp. 170-198, Simon \& Schuster, New York.

Ewell, P., 2007, 'Organizing for learning: A new imperative', American Association for Higher Education Bulletin, Washington, DC.

Freire, P., 1972, Pedagogy of the oppressed, Penguin, Harmondsworth.

Garrison, R., Anderson, T. \& Archer, W., 2003, 'A theory of critical inquiry in online distance education', in M.G. Moore \& W.G. Anderson (eds), Handbook for distance education, pp. 113-127, Erlbaum, Mahwah.

Glaser, B.G. \& Strauss, A., 1967, Discovery of grounded theory, Aldine, Chicago.

Gunawardena, C.N., Lowe, C.A. \& Anderson, T., 1997, 'Analysis of a global online debate and the development of an interaction analysis model for examining social construction of knowledge in computer conferencing', Journal of Educational Computing Research 17(4), 397-431. http://dx.doi.org/10.2190/7MQV-X9UJC7Q3-NRAG

Hammett, R. \& Collins, A., 2002, 'Knowledge construction and dissemination in graduate education', Canadian Journal of Education 27(4), 439-453. http://dx.doi. org/10.2307/1602244

Hmelo-Silver, C.E. \& Barrows, H.S., 2006, 'Goals and strategies of a problem-based learning facilitator', The Interdisciplinary Journal of Problem-based Learning 1(1) 21-39.

Jakovljevic, M., 2002, 'An instructional model for teaching complex thinking through web page design', doctoral thesis, School of Economics and Business Sciences, Rand Afrikaans University, Johannesburg.
Jonassen, D.H., 2000, 'Toward a design theory of problem solving', Educational Technology Research \& Technology 48(4), 63-85. http://dx.doi.org/10.1007/ BF02300500

Lave, J. \& Wenger, E., 1991, Situated learning: Legitimate peripheral participation, Cambridge University Press. http://dx.doi.org/10.1017/СBO9780511815355

Lazarus, J., 2005, 'Community engagement and service learning in South African higher education', paper delivered at the SAARDHE Conference, Durban Institute of Technology, Durban, 9-13 June 2004.

Lombardi, M.M., 2007, Authentic learning for the 21st century: An overview, Educause Learning Initiative, Boulder, viewed 1 November 2011, from http://net.educause. edu/ir/library

Lu, L.L. \& Jeng, I., 2006, 'Knowledge construction in inservice teacher online discourse: Impacts of instructor roles and facilitative strategies', Journal of Research on Technology in Education 39(2), 183-202.

Mandl, H., Gruber, H. \& Renkl, A., 1996, 'Communities of practice toward expertise: Social foundation of university instruction', in P.B. Baltes \& U. Staudinger (eds.) Interactive minds: Life-span perspectives on the social foundation of cognition Cambridge University Press, Cambridge.

Maor, D., 2007, 'The cognitive and social processes of how university students experience online learning', in ICT: Providing choices for learners and learning, Ascilite 2007 proceedings, Singapore, 2-5 December 2007, viewed 24 April 2013 from http://www.ascilite.org.au/conferences/singapore07/procs/maor.pdf

Maree, C., Van der Walt, C. \& Van Rensburg, G., 2009, 'Model for the education of neonatal nurses as reflective practitioners', Acta Academica 41(3), 61-85.

McLoughlin, C. \& Luca, J., 2001, 'Assessment methodologies in transition: Changing practices in web-based learning', in L. Richardson \& J. Lidstone (eds), Flexible learning for a flexible society, ASET-HERDSA 2000 Conference proceedings, Toowoomba, New Zealand, 2-5 July 2000, pp. 516-526.

Moore, J.L. \& Marra, R.M., 2005, 'A comparative analysis of online discussion participation protocols', Journal of Research on Technology in Education 38(2), 191-212.

Mtshali, N.G., 2009, 'Conceptualisation of community-based education in South Africa: A grounded theory analysis', Curationis, 5, 5-12.

Oliver, R., Harper, B., Hedberg, J., Wills, S. \& Agostinho, S., 2002, Formalizing the description of learning designs, 2002 Annual HERDSA Conference proceedings, description of learning designs, 2002 Annual HERDSA Conference proceedings,
Perth, Australia, 7-10 July 2002, viewed 23 October 2010, from http://www. Perth, Australia, 7-10 July
learningdesigns.uow.edu.au

Peterson, M., 2010, 'Enhance problem-based learning', Medical Education Online $2(3), 35-49$

Savery, J.R., 2006, 'Overview of problem-based learning: Definitions and distinctions', Interdisciplinary Journal of Problem-based Learning 1(1), 9-20.

Schellens, T. \& Valcke, M., 2006, 'Fostering knowledge construction in university students through asynchronous discussion groups', Computers \& Education 46(4), 349-370. http://dx.doi.org/10.1016/j.compedu.2004.07.010

Schön, D.A., 1987, Teaching artistry through reflection in action: Educating the reflective practitioner, Jossey-Bass, San Francisco.

Smith, B.L., 2010, 'Learning communities and liberal education', Academe 89(1), 1418. http://dx.doi.org/10.2307/40252241

Stover, D., 2001, 'Applying brain research in the classroom is not a brainer', Education Digest 66(8), 26-29.

Strauss, A. \& Corbin, J., 1990, Basics of qualitative research: Grounded theory, procedures and techniques, Sage, Newbury Park.

Trochim, W.M.K., 2002, Ethics in research, viewed 15 February 2013, from http:// www.socialresearchmethods.net/kb/ethics.htm

Von Glasersfeld, E., 1995, 'A constructivist approach to teaching', in L. Steffe \& J. Gale (eds), Constructivism in education, pp. 3-16, Erlbaum, Hillsdale.

Wilson, B.B., 1997, Thoughts on theory in educational technology, viewed 17 August 2009, from http://carbon.cudernver.edu bwilson/theory.html

Winberg, C., 2006, 'Undisciplining knowledge production: Development driven higher education in South Africa', Higher Education 51, 159-172. http://dx.doi. org/10.1007/s10734-004-6378-5

Windschitl, M., 2002, 'Framing constructivism in practice as the negotiation of dilemmas: An analysis of the conceptual, pedagogical, cultural, and political challenges facing teachers', Review of Educational Research 72(2), 131-175. http://dx.doi.org/10.3102/00346543072002131

Yueng, K. \& Hau, K., 2006, 'Constructivists teaching and teacher-centred teaching A comparison of students' learning in a university course', Innovation in Education \& Teaching International 43(3), 279-290. http://dx.doi. org/10.1080/14703290600750861 